\title{
p38 $\alpha$ Regulates Expression of DUX4 in a Model of Facioscapulohumeral Muscular Dystrophy ${ }^{[}$
}

\author{
L. Alejandro Rojas, Erin Valentine, Anthony Accorsi, Joseph Maglio, Ning Shen, \\ Alan Robertson, Steven Kazmirski, Peter Rahl, Rabi Tawil, Diego Cadavid, \\ Lorin A. Thompson, Lucienne Ronco, Aaron N. Chang, Angela M. Cacace, \\ and Owen Wallace
}

Fulcrum Therapeutics, Cambridge, Massachusetts (L.A.R., E.V., A.A., J.M., N.S., A.R., S.K., P.R., D.C., L.A.T., L.R., A.N.C., A.M.C., O.W.) and University of Rochester Medical Center, Department of Neurology, Rochester, New York (R.T.)

Received December 16, 2019; accepted May 26, 2020

\begin{abstract}
Facioscapulohumeral muscular dystrophy (FSHD) is caused by the loss of repression at the $D 4 Z 4$ locus leading to aberrant double homeobox 4 (DUX4) expression in skeletal muscle. Activation of this early embryonic transcription factor results in the expression of its target genes causing muscle fiber death. Although progress toward understanding the signals driving DUX4 expression has been made, the factors and pathways involved in the transcriptional activation of this gene remain largely unknown. Here, we describe the identification and characterization of p38 $\alpha$ as a novel regulator of DUX4 expression in FSHD myotubes. By using multiple highly characterized, potent, and specific inhibitors of p38 $\alpha / \beta$, we show a robust reduction of DUX4 expression, activity, and cell death across patient-derived FSHD1 and FSHD2 lines. RNA-seq profiling reveals that a small number of genes are differentially expressed upon $p 38 \alpha / \beta$ inhibition, the vast majority
\end{abstract}

\section{Introduction}

Facioscapulohumeral muscular dystrophy (FSHD) is a rare and disabling condition with an estimated worldwide population prevalence of between 1 in 8000 and 20,000 (Deenen et al., 2014; Statland and Tawil, 2014). Most cases are familial and inherited in an autosomal dominant fashion, and about $30 \%$ of cases are known to be sporadic. FSHD is characterized by progressive skeletal muscle weakness affecting the face, shoulders, arms, and trunk, which is followed by weakness of the distal lower extremities and pelvic girdle (Tawil et al., 2015). There are currently no approved treatments for this condition.

Financial disclosure: L.A.R., E.V., A.A., J.M., N.S., A.R., S.K., P.R., D.C., L.A.T., L.R., A.N.C., A.M.C., and O.W. are or have been employees and stockholders at Fulcrum Therapeutics.

An earlier version of this paper appears in bioRxiv under the DOI: https:// doi.org/10.1101/700195.

https://doi.org/10.1124/jpet.119.264689.

S This article has supplemental material available at jpet.aspetjournals.org. of which are DUX4 target genes. Our results reveal a novel and apparently critical role for p38 $\alpha$ in the aberrant activation of DUX4 in FSHD and support the potential of $\mathrm{p} 38 \alpha / \beta$ inhibitors as effective therapeutics to treat FSHD at its root cause.

\section{SIGNIFICANCE STATEMENT}

Using patient-derived facioscapulohumeral muscular dystrophy (FSHD) myotubes, we characterize the pharmacological relationships between p38 $\alpha / \beta$ inhibition, double homeobox 4 (DUX4) expression, its downstream transcriptional program, and muscle cell death. p38 $\alpha / \beta$ inhibition results in potent and specific DUX4 downregulation across multiple genotypes without significant effects in the process of myogenesis in vitro. These findings highlight the potential of $\mathrm{p} 38 \alpha / \beta$ inhibitors for the treatment of FSHD, a condition that today has no approved therapies.

ABBREVIATIONS: abs $(\mathrm{FC})$, absolute fold change; $\mathrm{BET}$, bromodomain and extraterminal motif protein; DNMT3B, DNA methyltransferase 3B; DUX4, double homeobox 4; FDR, false discovery rate; FSHD, facioscapulohumeral muscular dystrophy; HMBS, hydroxymethylbilane synthase; HSP27, heat shock protein 27; MAPK, mitogen-activated protein kinase; MBD, methyl-CpG binding protein-like; MHC, myosin heavy chain; MSD, Mesoscale Diagnostics; MYOG, myogenin; POLR2A, RNA polymerase II subunit A; qPCR, quantitative polymerase chain reaction; RT, reverse transcription; RU, repeat unit; siRNA, small interfering RNA; SLC34A2, solute carrier 34A2; SMCHD1, structural maintenance of chromosomes flexible hinge domain containing 1; TRIM, tripartite motif-containing. 
such as DNMT3B, are thought to also participate in the establishment of silencing of this region (van den Boogaard et al., 2016b).

DUX4 expression in skeletal muscle as a result of the $D 4 Z 4$ repeat contraction or $S M C H D 1$ mutations leads to activation of a downstream transcriptional program that causes FSHD (Yao et al., 2014; Jagannathan et al., 2016; Shadle et al., 2017). Major target genes of DUX4 are members of the DUX family itself and other homeobox transcription factors. Additional target genes include highly homologous gene families, including the preferentially expressed in melanoma family (PRAMEF), tripartite motif-containing (TRIM), and methyl-CpG-binding protein-like (MBD3L) (Geng et al., 2012; Tawil et al., 2014; Yao et al., 2014; Shadle et al., 2017). Expression of DUX4 and its downstream transcriptional program in skeletal muscle cells is toxic, leading to dysregulation of multiple pathways and resulting in impairment of contractile function and cell death (Bosnakovski et al., 2014; Tawil et al., 2014; Himeda et al., 2015; Homma et al., 2015; Rickard et al., 2015; Statland et al., 2015).

Several groups have made progress toward understanding the molecular mechanisms regulating DUX4 expression (van den Boogaard et al., 2016a,b; Campbell et al., 2017, 2018; Cruz et al., 2018; Oliva et al., 2019). However, factors that drive transcriptional activation of DUX4 in patients with FSHD are still largely unknown. By screening our annotated chemical probe library to identify disease-modifying small-molecule drug targets that reduce DUX4 expression in FSHD myotubes, we have identified multiple chemical scaffolds that inhibit $\mathrm{p} 38 \alpha$ and $\beta$ mitogen-activated protein kinase (MAPK). We found that inhibitors of $\mathrm{p} 38 \alpha$ kinase or its genetic knockdown reduce DUX4 and its downstream gene expression program in FSHD myotubes, thereby impacting the core pathophysiology of FSHD.

Members of the p38 MAPK family composed of $\alpha, \beta, \gamma$, and $\delta$, isoforms are encoded on separate genes and play a critical role in mediating cellular responses to extracellular signals (Whitmarsh, 2010). In many inflammatory, cardiovascular, and chronic disease states, p38 MAPK stress-induced signals can trigger maladaptive responses that aggravate rather than alleviate the disease process (Krementsov et al., 2013; Martin et al., 2015). Similarly, in skeletal muscle, a variety of extracellular signals, including exercise, insulin exposure, myoblast differentiation, and reactive oxygen species as well as apoptosis, have all been shown to induce the p38 kinase pathways (Zarubin and Han, 2005; Keren et al., 2006). Downstream substrates of p38 MAPK include other kinases, downstream effectors like heat shock protein 27 (HSP27), and modulation of transcription factor activity culminating in gene expression changes (Kyriakis and Avruch, 2001; Cuenda and Rousseau, 2007).

p38 $\alpha$ is the most abundantly expressed isoform in skeletal muscle, and it plays an important role controlling the activity of transcription factors that drive myogenesis (Simone et al., 2004; Knight et al., 2012; Segalés et al., 2016b). p38 $\alpha$ abrogation in mouse myoblasts inhibits fusion and myotube formation in vitro (Zetser et al., 1999; Perdiguero et al., 2007). However, conditional ablation of p38 $\alpha$ in the adult mouse skeletal muscle tissue appears to be well-tolerated and alleviates phenotypes observed in models of other muscular dystrophies (Wissing et al., 2014).

Here, we show that selective $\mathrm{p} 38 \alpha / \beta$ inhibitors potently decrease the expression of DUX4, its downstream gene program, and cell death in FSHD myotubes across a variety of FSHD1 and FSHD2 genotypes. Using RNA-seq and high-content image analysis, we also demonstrated that myogenesis is not affected at concentrations that result in downregulation of DUX4.

\section{Materials and Methods}

Cell Lines and Cell Culture. Immortalized myoblasts from FSHD (AB1080FSHD26 C6) and healthy individuals (AB1167C20FL) were generated and obtained from the Institut Myologie, France. In short, primary myoblast cultures were obtained from patient samples and immortalized by overexpression of telomerase reverse transcriptase (TERT) and cyclin-dependent kinase 4 (CDK4) (Krom et al., 2012). Primary myoblasts were isolated from FSHD muscle biopsies and were obtained from University of Rochester.

Immortalized myoblasts were expanded on gelatin-coated dishes (ES-006-B; EMD Millipore) using skeletal muscle cell growth media (C-23060; Promocell) supplemented with 15\% FBS (16000044; ThermoFisher). Primary myoblasts were also expanded on gelatin-coated plates but using media containing Ham's F-10 Nutrient Mix (11550043; ThermoFisher), 20\% FBS, and 0.5\% chicken embryo extract (100-163P; Gemini Bio-product). For differentiation, immortalized or primary myoblasts were grown to confluency in matrigelcoated plates (356234; Corning), and growth media was exchanged for differentiation media (Nb4-500; Brainbits) after a PBS wash. DMSO (vehicle) or compounds (previously dissolved in DMSO at 10-mM stock concentrations) were added at the desired concentration at the time differentiation media was exchanged and maintained in the plates until harvesting or analysis.

Small-Molecule Compounds and Antisense Oligonucleotides. SB239063, Pamapimod, LY2228820, and Losmapimod were purchased from Selleck Chem (S7741, S8125, S1494, and S7215). Ten-millimolar stock solutions in DMSO were maintained at room temperature away from light. DUX4 antisense oligonucleotides (gapmer) were purchased from Qiagen and were designed to target exon 3 of DUX4. The lyophilized oligos were resuspended in PBS at 25$\mathrm{mM}$ final concentration and kept frozen at $-20^{\circ} \mathrm{C}$ until used. This antisense oligonucleotide was added to cells in growth media 2 days before differentiation and maintained during the differentiation process until harvesting.

Detection of DUX4 and Target Gene Expression by Reverse-Transcription Quantitative Polymerase Chain Reaction. RNA from myotubes was isolated from C6 FSHD cells differentiated in six-well plates using $400 \mu$ l of trireagent and transfer to Qiagen qiashredder column (cat. 79656). An equal amount of $100 \%$ ethanol was added to flow through and transferred to a Direct-zol microcolumn (cat. 2061; Zymo research), and the manufacturer's protocol, including on-column DNA digestion, was followed. RNA (1 $\mu \mathrm{g})$ was converted to cDNA using Superscript IV priming with oligodeoxythymine (cat. 18091050; Thermofisher). Preamplication of DUX4 and housekeeping gene HMBS was performed using preamp master mix (cat. 4384267; Thermofisher) as well as $0.2 \times$ diluted taqman assays (IDT DUX4 custom; Forward: $5^{\prime}$-GCCGGCCCAGGT ACCA-3', Reverse: 5'-CAGCGAGCTCCCTTGCA-3', and Probe: 5 '56-FAM/CAGTGCGCA/ZEN/CCCCG/3IABkFQ/-3'; and HMBS HS00609297m1-VIC). After 10 cycles of preamplification, reactions were diluted 5 -fold in nuclease-free water, and quantitative polymerase chain reaction ( $\mathrm{qPCR}$ ) was performed using Taqman Multiplex Master Mix (cat. 4461882; Thermofisher).

To measure DUX4 target gene expression in a 96-well plate format, cells were lysed into $25 \mu$ l Realtime Ready lysis buffer (07248431001; Roche) containing 1\% RNAse inhibitor (03335399001; Roche) and $1 \%$ DNase I (AM2222; ThermoFisher) for 10 minutes while being shaken on a vibration platform shaker (1000; Titramax) at $1200 \mathrm{rpm}$. After homogenization, lysates were frozen at $-80^{\circ} \mathrm{C}$ for at least 30 minutes and thawed on ice. Lysates were diluted to $100 \mu \mathrm{l}$ using 
A

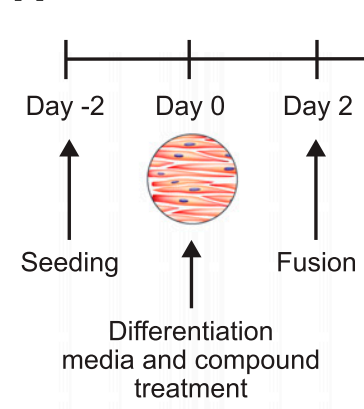

C

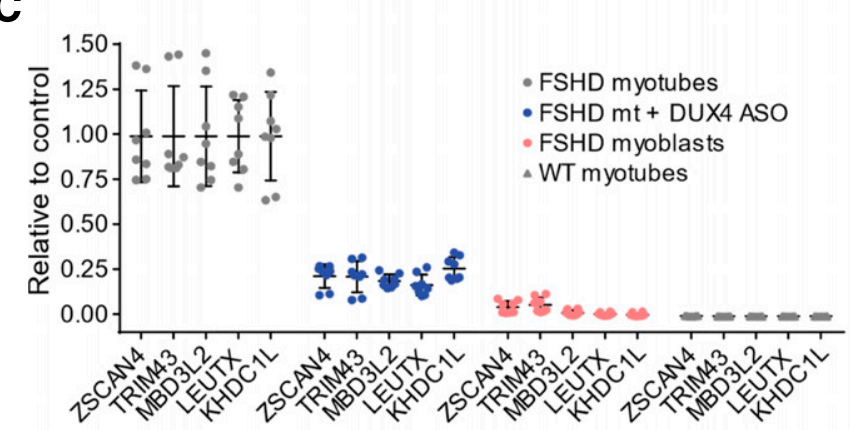

B

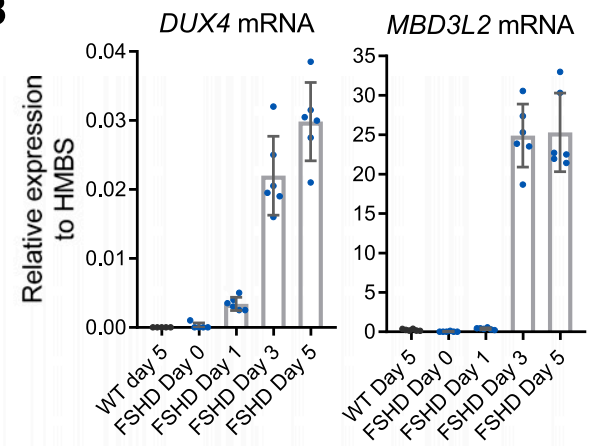

E
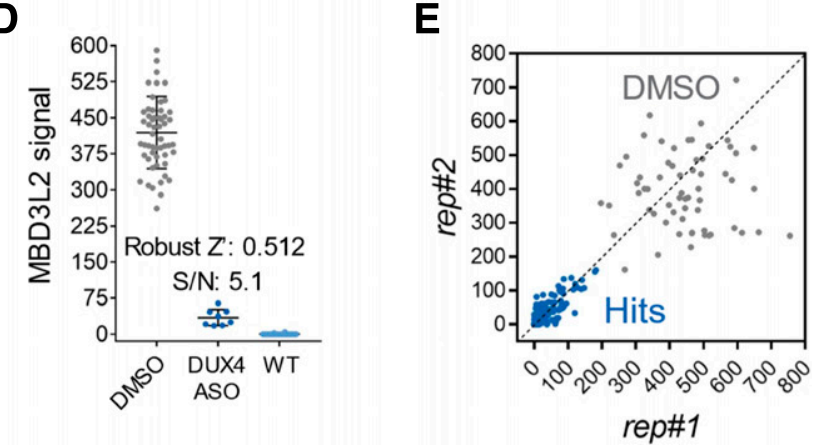

Fig. 1. Description of an assay for the identification of inhibitors of DUX4 expression. (A) Schematic describing the cellular assay used to identify small molecules that result in the inhibition of DUX4 expression and activity. In short, immortalized FSHD myoblasts (C6, 6.5 D4Z4 RUs) were seeded in 96well plates 2 days before differentiation was induced. After myoblasts reached confluence, media was replaced, and compounds for treatment were added. At day 2, fusion was observed, and at day 5, differentiated myotubes were harvested for gene expression analysis or fixed for immunostaining. Representative image of the $\alpha$-actinin staining in differentiated myotubes. (B) DUX4 expression is rapidly induced after differentiation of immortalized FSHD myotubes in vitro. To measure DUX4 transcript, C6 FSHD myotubes were grown in 12-well plates similarly to (A), and cells were harvested on day 5 for RNA extraction. RT-qPCR was used to determine expression of DUX4 mRNA and its downstream gene MBD3L2 (normalized using $H M B S$ as housekeeping). These transcripts were not detected in wild-type immortalized myotubes derived from healthy volunteers. (C) Canonical DUX4 target genes are specifically detected in FSHD myotubes and are downregulated when DUX4 is knocked down using a specific antisense oligonucleotide. RTqPCR analysis was used to detect expression in immortalized myoblasts/myotubes. Antisense oligonucleotide knockdown in FSHD myotubes (mt) was carried out during the 5 days of differentiation. Bars indicate mean \pm S.D. (D) A 96 -well plate cell-based assay was optimized to screen for inhibitors of DUX4 expression. An assay measuring $M B D 3 L 2$ by RT-qPCR was selected because of robust separation and specificity reporting DUX4 activity. MBD3L2 signal was normalized using POLR2A as a housekeeping gene. Bars indicate mean \pm S.D. (E) Hits identified in small-molecule screen potently reduced the activity of DUX4. $x$ - and $y$-axis show the normalized MBD3L2 signal obtained from the two replicate wells analyzed. ASO, antisense oligonucleotide; KHDC1L, K homology domain containing 1 like; LEUTX, leucine twenty homeobox; WT, wild type; ZSCAN4, zinc finger and SCAN domain containing $4 ; \mathrm{S} / \mathrm{N}$, signal to noise ratio; rep, replicate.

RNase-free water. One microliter of this reaction was used for reverse transcription and preamplification of cDNA in a 5- $\mu$ l one-step reaction using the reverse-transcription (RT) enzyme from Taqman RNA-to-Ct (4392938; ThermoFisher) and the Taqman Preamp Master Mix (4391128; ThermoFisher) according to manufacturer's specifications. This preamplification reaction was diluted 1:4 using nuclease-free water; $1 \mu l$ of this reaction was used as input for a $5-\mu l$ qPCR reaction using the Taqman Multiplex Master Mix (4484262; ThermoFisher). Amplification was detected in a Quantstudio 7 Flex instrument from ThermoFisher. The following Taqman probes were purchased from ThermoFisher: MBD3L2 Taqman Assay [Hs00544743_m1, FAM-MGB; ThermoFisher, (Bosnakovski et al., 2019)], zinc finger and SCAN domain containing 4 (ZSCAN4) Taqman Assay (Hs00537549_m1, FAM-MGB; ThermoFisher), leucine twenty homeobox (LEUTX) Taqman Assay (Hs01028718_m1, FAM-MGB; Thermo Fisher), TRIM43 Taqman Assay (Hs00299174_m1, FAM-MGB; ThermoFisher), K homology domain containing 1 like (KHDC1L) Taqman Assay (Hs01024323_g1, FAM-MGB; ThermoFisher), and RNA Polymerase II Subunit A (POLR2A) Taqman Assay (Hs00172187_m1, VIC-MGB; ThermoFisher).

Detection of HSP27 by Electrochemiluminescence. Total and phosphorylated HSP27 was measured using a commercial MesoScale Discovery assay, Phospho (Ser82)/Total HSP27 Whole Cell Lysate Kit (K15144D; MesoScale Discovery). Myotubes were grown in 96-well plates using conditions described above and were lysed using $25 \mu$ of $1 \times$ Mesoscale Diagnostics (MSD) lysis buffer with protease and phosphatase inhibitors. The lysates were incubated at room temperature for 10 minutes with shaking at $1200 \mathrm{rpm}$ using Titramax 1000. Lysates were stored at $-80^{\circ} \mathrm{C}$ until all timepoints were collected. Lysates were then thawed on ice, and $2 \mu \mathrm{l}$ were used to perform a BCA protein assay (23225; ThermoFisher). Ten microliters of lysate were diluted 1:1 in 1× MSD lysis buffer and added to the 96well Mesoscale assay plate. Manufacturer instructions were followed, and data were obtained using a MesoScale Discovery SECTOR S 600 instrument.

Myotube Nuclei Isolation and Detection of DUX4 by Electrochemiluminescence. DUX4 was measured using a novel MesoScale Discovery assay developed at Fulcrum Therapeutics. Anti-DUX4 monoclonal capture antibody (clone P2B1) was coated overnight at $5 \mu \mathrm{g} / \mathrm{ml}$ in $0.1 \mathrm{M}$ sodium bicarbonate $(\mathrm{pH}=8.4)$ onto a Mesoscale 384well plate (L21XA). The plate was blocked with $5 \%$ bovine serum albumin/PBS for at least 2 hours. Human FSHD myotubes grown in $100-\mathrm{mm}$ plates in the conditions described above were harvested 4 days postdifferentiation using TrypLE express solution (12605-010; Gibco) and neutralized with growth media, and the myotubes were pelleted by centrifugation. Myotubes were resuspended in ice-cold nuclei extraction buffer ( $320 \mathrm{mM}$ sucrose, $5 \mathrm{mM} \mathrm{MgCl}_{2}, 10 \mathrm{mM}$ HEPES, $1 \%$ Triton $\mathrm{X}-100$ at $\mathrm{pH}=7.4$ ). Nuclei were pelleted by centrifugation at $2000 \mathrm{~g}$ for 4 minutes at $4^{\circ} \mathrm{C}$. Nuclei were resuspended in ice-cold wash buffer ( $320 \mathrm{mM}$ sucrose, $5 \mathrm{mM} \mathrm{MgCl}_{2}, 10 \mathrm{mM}$ HEPES at $\mathrm{pH}=7.4$ ) and pelleted by centrifugation at $2000 \mathrm{~g}$ for 4 minutes at $4^{\circ}$ C. Nuclei were suspended in $150 \mu \mathrm{l}$ of RIPA buffer at $4^{\circ} \mathrm{C}(+150 \mathrm{mM}$ 

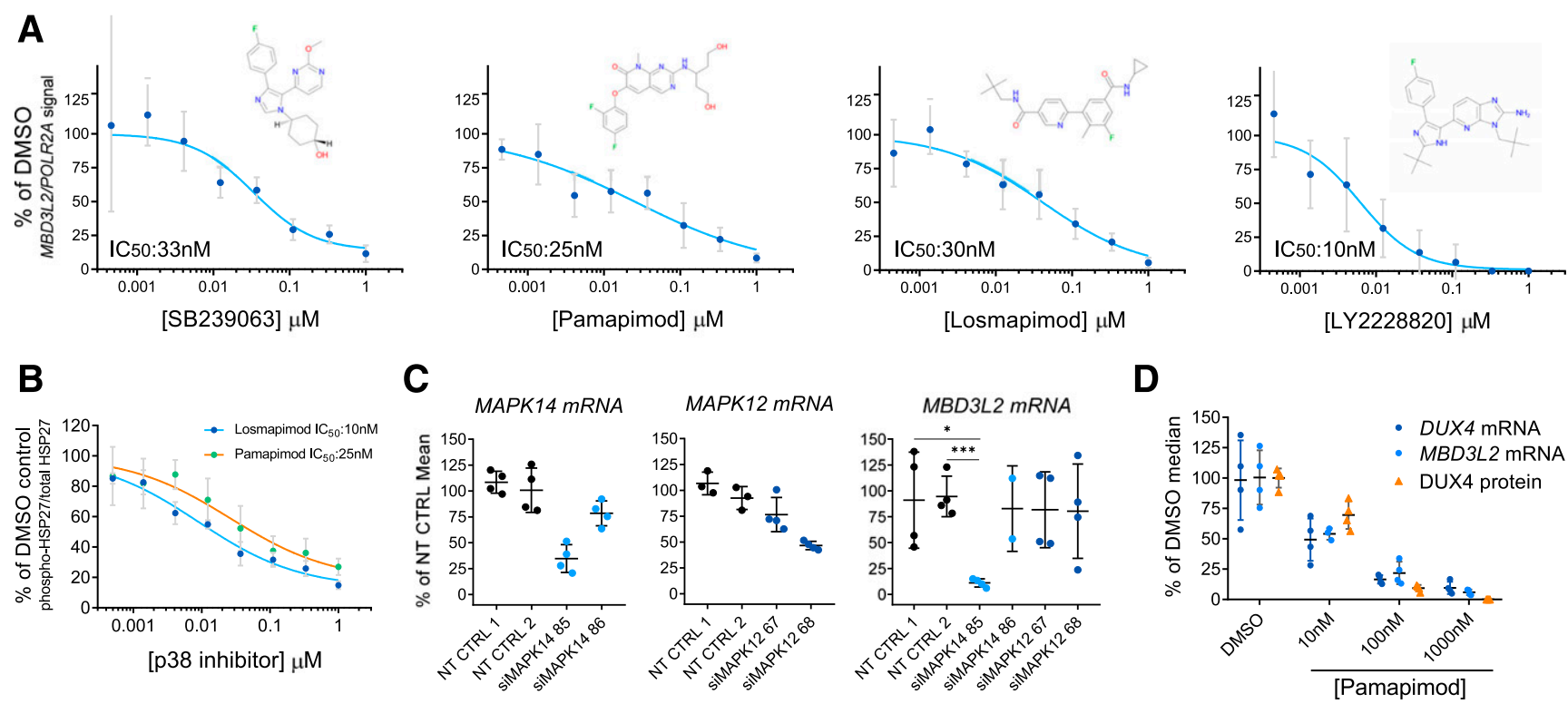

Fig. 2. Small-molecule inhibitors of p38 $\alpha$-reduced expression of DUX4 in FSHD myotubes. (A) Diverse inhibitors of p38 $\alpha / \beta$ reduce the expression of MBD3L2 in differentiating FSHD myotubes. Concentration-dependent responses were observed with all tested inhibitors. Four replicates per concentration were tested to measure reduction of MBD3L2 in immortalized C6 FSHD myotubes, and bars indicate mean \pm S.D. (B) p38 $\alpha / \beta$ pathway inhibition in C6 FSHD myotubes. The ratio between phosphorylated HSP27 to total HSP27 was measured by an immunoassay (MSD) after 12 hours of treatment of C6 FSHD myotubes with the indicated inhibitors. IC 50 observed for phosphorylated HSP27 (p-HSP27) were comparable to those obtained for reduction of $M B D 3 L 2$ expression. Bars indicate mean \pm S.D. for four replicate wells. (C) Knockdown of p38 $\alpha$ (MAPK14) results in reduction of MBD3L2 expression. Immortalized C6 myoblasts were electroporated with siRNAs specific for MAPK14 (p38 $\alpha$ ) and MAPK12 (p38 $\gamma$ ) plated and differentiated for 3 days. Expression of the indicated transcripts was measured using RT-qPCR and normalized against POLR2A. Reduction of MBD3L2 expression was observed when $>50 \%$ knockdown of $M A P K 14$ was achieved. Bars indicate mean \pm S.D. (D) p38 $\alpha / \beta$ inhibition results in the reduction of DUX4 expression. After inhibition, correlated reduction of DUX4 mRNA, protein and downstream gene MBD3L2 was observed. To measure DUX4 protein, a novel immunoassay was developed using previously described antibodies (see Materials and Methods and Supplemental Fig. 4). Bars indicate mean \pm S.D., $t$ test $P$ value $*<0.01$, *** 0.0002. CTRL, control; si, small interfering; NT, non-targeting.

$\mathrm{NaCl})$. Extracts were diluted 1:1 with assay buffer, and $10 \mu \mathrm{l}$ per well was added to 384-well precoated/blocked MSD plate and incubated for 2 hours. Anti-DUX4-sulfo conjugate (clone E5-5) was added to each well and incubated for 2 hours. Plates were washed, and $40 \mu l$ per well of $1 \times$ Read $T$ buffer was added. Data were obtained using a MesoScale Discovery SECTOR S 600 instrument.

Quantitative Immunofluorescent Detection of Myosin Heavy Chain, Solute Carrier 34A2, and Cleaved Caspase-3. Myotubes were grown and treated as described above. At day 5 after differentiation was induced, cells were fixed using $4 \%$ paraformaldehyde in PBS during 10 minutes at room temperature. Fixative was washed, and cells were permeabilized using $0.5 \%$ Triton X-100 during 10 minutes at room temperature. After washing, fixing, and permeabilizing, the cells were blocked using 5\% donkey serum in PBS/0.05\% Tween 20 during 1 hour at room temperature. Primary antibodies against myosin heavy chain (MHC) (MF20, MAB4470; R\&D systems), solute carrier 34A2 (SLC34A2) (66445; Cell signaling), and active Caspase-3 (9661; Cell signaling) were diluted 1:500 in PBS containing 0.1\% Triton X-100 and 5\% donkey serum and incubated with cells for 1 hour at room temperature. After four washes, secondary antibodies were added (A32723 and R37117; ThermoFisher) in a 1:2000 dilution and incubated during 1 hour at room temperature. During the last 5 minutes of incubation, a 1:2000 dilution of DAPI (4',6-diamidino-2-phenylindole) was added before proceeding with final washes and imaging. Images were collected using the CellInsight CX7 (ThermoFisher). Images were quantified using HCS Studio Software. Differentiation was quantified by counting the percentage of nuclei in cells expressing MHC from the total of the well. SLC34A2 and active Caspase-3 signal were quantified by colocalization of cytoplasmic cleaved Caspase-3 within MHCexpressing cells.

Knockdown of MAPK12 and MAPK14 in FSHD Myotubes. Exponentially dividing immortalized C6 FSHD myoblasts were harvested and counted. Fifty thousand myoblasts were electroporated using a $10-\mu$ lip in a neon electroporation system (ThermoFisher).
Conditions used were determined to preserve viability and achieved maximal electroporation (pulse $\mathrm{V}=1100 \mathrm{~V}$, pulse width $=40$ and pulse $\#=1$ ). After electroporation, cells were plated in growth media, and media was changed for differentiation 24 hours after. Three days after differentiation, cells were harvested and analyzed for knockdown and effects in MBD3L2 using the RT-qPCR assay described before. siRNAs used were obtained from ThermoFisher (4390843, 4390846, s3585, s3586, s12467, s12468).

Gene Expression Analysis by RNA-seq. RNA from myotubes grown in six-well plates in conditions described above was isolated using the RNeasy Micro Kit from Qiagen (74004). Quality of RNA was assessed by using a Bioanalyzer 2100, and samples were submitted for library preparation and deep sequencing to the molecular biology core facility at the Dana Farber Cancer Institute. After sequencing, raw reads of fastq files from all samples were mapped to hg38 genome assemblies using ArrayStudio aligner. Raw read count and FPKM (fragments per kilobase of exon model per million reads mapped) were calculated for all the genes, and DESeq2 was applied to calculate differentially expressed genes using general linear model. Statistical cutoff of absolute fold change [abs $(\mathrm{FC})>4$, FDR $<0.001]$ were applied to identify differentially expressed protein coding genes. The data in this publication is accessible through GEO Series accession number GSE153301 (https://www.ncbi.nlm.nih.gov/geo/query/acc.cgi? acc $=$ GSE153301).

\section{Results}

Identification of Inhibitors of DUX4 Expression. To model FSHD in vitro, we differentiated patient-derived FSHD1 immortalized myoblasts into skeletal muscle myotubes. We allowed myoblasts to reach $>70 \%$ confluency and added differentiation medium lacking growth factors (Fig. 1A) (Brewer et al., 2008; Krom et al., 2012; Thorley et al., 2016). 


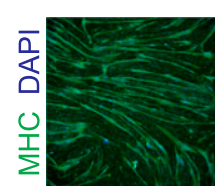

DMSO

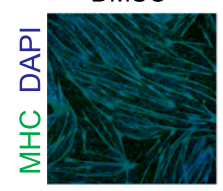

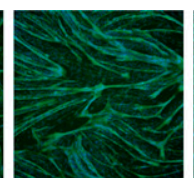

1000

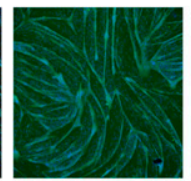

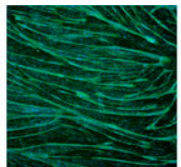

333

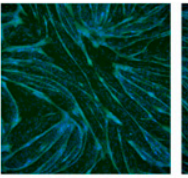

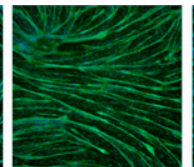

111

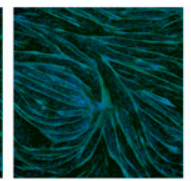

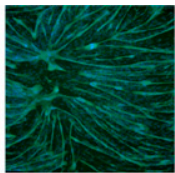

$37 \mathrm{nM}$

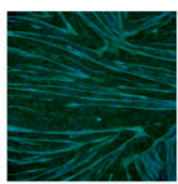

Losmapimod

B

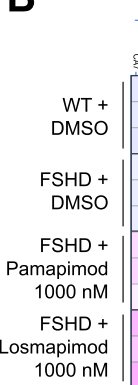

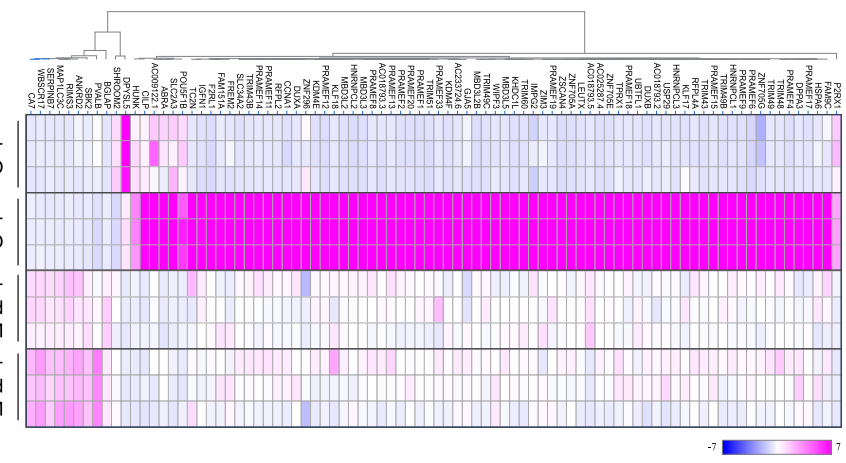

\section{C}
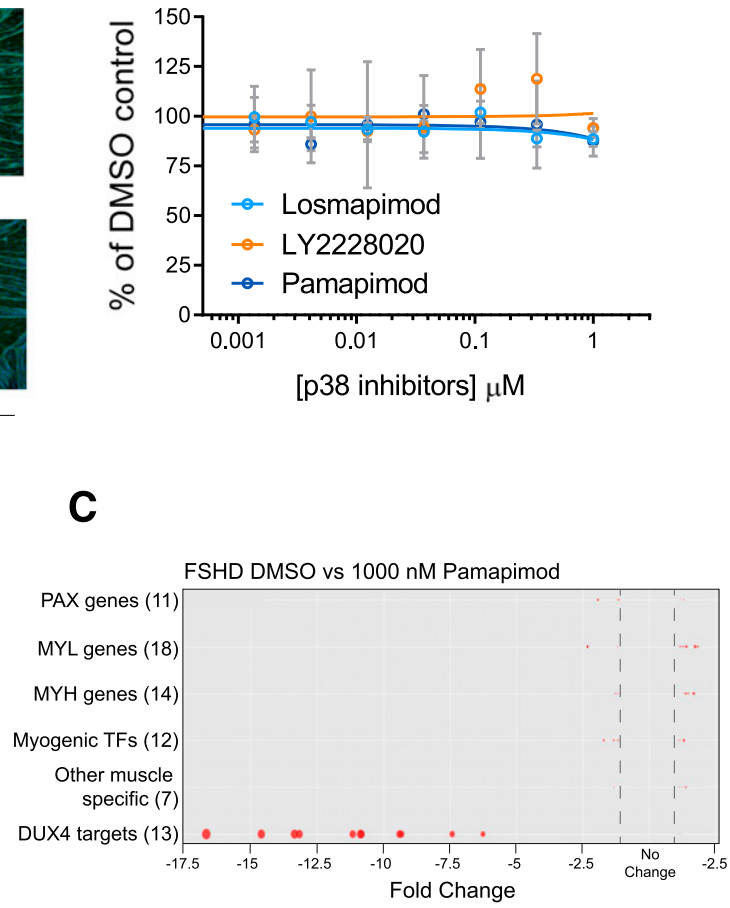

Fig. 3. Inhibition of the p38 $\alpha / \beta$ pathway results in normalized gene expression in FSHD myotubes without affecting the differentiation process in vitro. (A) Quantification of myotube differentiation after p38 $\alpha / \beta$ inhibition. Two inhibitors were used to demonstrate the effects of p38 $\alpha / \beta$ inhibition in a highcontent imaging assay to quantify the number of nuclei that properly underwent differentiation by activation of expression of myofiber specific proteins (i.e., MHC). No changes were observed in the morphology of $\mathrm{C} 6$ myotubes treated for 5 days. Bars indicate mean \pm S.D. (B) Heat map representing fold change of expression levels of differentially expressed genes after p38 $\alpha / \beta$ inhibition in FSHD myotubes for 5 days. Eighty-six genes showed significant changes in expression after treatment with two different inhibitors [abs $(\mathrm{FC})>4$; FDR $<0.001]$. Each condition was tested in triplicate represented as rows in the heatmap. (C) DUX4 target genes are specifically downregulated by p38 inhibition. $x$-Axis indicates the fold changes observed in members of the gene families indicated. Diameter of dots represent $P$ value. DAPI, 4',6-diamidino-2-phenylindole; PAX, paired box; WT, wild type; MYL, Myosin Light Chain; MYH, Myosin Heavy Chain; TF, transcription factor.

After 1 day of differentiation, we detected DUX4 expression by RT-qPCR, and its expression increased throughout the course of myogenic fusion and formation of postmitotic, multinucleated FSHD myotubes (Fig. 1B). Because of the stochastic and low expression levels of DUX4 in FSHD cells, we measured DUX4-regulated genes as an amplified readout of the expression and activity of DUX4. These include ZSCAN4 (zinc finger and SCAN domain containing 4), MBD3L2, TRIM43, LEUTX (leucine twenty homeobox), and KHDC1L (K homology domain containing 1 like), which are among the most commonly described DUX4 targets (Geng et al., 2012; Tasca et al., 2012; Yao et al., 2014; Jagannathan et al., 2016; Chen et al., 2016b; Whiddon et al., 2017; Wang et al., 2019). These genes were downregulated after DUX4 antisense oligonucleotide treatment of FSHD myotubes and were nearly undetectable or completely absent in FSHD myoblasts or wild-type myotubes (Fig. 1C). We concluded that the assays used to detect these transcripts were specific because their expression was solely dependent on DUX4 expression in differentiating myotubes. Although a number of DUX4-dependent transcripts have been previously described, we selected an assay to specifically detect MBD3L2 for high-throughput screening because it displayed the best signal window of differential expression in our in vitro system comparing FSHD to healthy wild-type myotubes (Fig. 1D). With this assay, we identified several small molecules that reduced MBD3L2 expression after 5 days of differentiation and treatment and showed good reproducibility across replicates (Fig. 1E). Validating our results, we found several molecules identified previously to reduce DUX4 expression, including BET inhibitors and $\beta$-adrenergic agonists exemplified in Supplemental Fig. 1 (Campbell et al., 2017; Cruz et al., 2018). However, when treating differentiating FSHD myotubes in our assay, we observed a reduction in fusion as indicated by visual inspection and by the reduction of $M Y O G$ expression with BET inhibitors. Importantly, we identified multiple scaffolds that inhibit $\mathrm{p} 38 \alpha$ and $\beta$ and strongly inhibit the expression of $M B D 3 L 2$ without affecting differentiation.

p38 $\alpha$ Signaling Participates in the Activation of DUX4 Expression in FSHD Myotubes. Potent and selective inhibitors of $\mathrm{p} 38 \alpha / \beta$ have been previously explored in multiple clinical studies for indications associated with the role of p38 $\alpha$ in the regulation of the expression of inflammatory cytokines and cancer (Coulthard et al., 2009). We tested several p38 $\alpha / \beta$ inhibitors of different chemical scaffolds in our assays, which showed significant inhibition of MBD3L2 expression (Fig. 2A). Importantly, $\mathrm{IC}_{50}$ obtained for $M B D 3 L 2$ reduction were comparable to reported values by other groups in unrelated cell-based assays that measured p38 $\alpha / \beta$ inhibition, suggesting the specificity for the assigned target (Underwood et al., 2000; Campbell et al., 2014; Fehr et al., 2015). p38 $\alpha$ and $\beta$ kinases phosphorylate a myriad of substrates, including downstream kinases like MAPK-activated protein kinase 2 (MAPKAPK2 or MK2), which phosphorylates effector molecules, such as HSP27 as well as a variety of transcription 
A
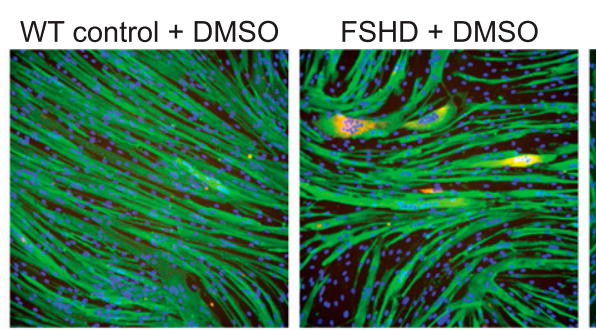

FSHD + Pamapimod(1mM)

DAPI MHC Cleaved Caspase-3

B
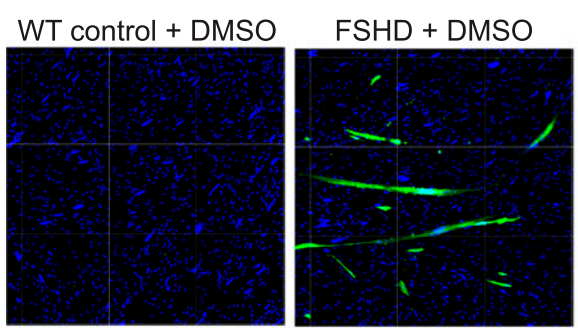

FSHD + Pamapimod(1mM)

C

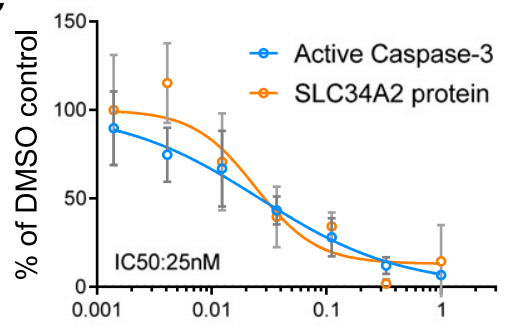

[Pamapimod] $\mu \mathrm{M}$

Fig. 4. Inhibition of the $\mathrm{p} 38 \alpha / \beta$ pathway reduced the activation of programmed cell death in differentiating FSHD myotubes. (A) A highcontent imaging assay was developed to measure cleaved caspase- 3 in differentiating myotubes. C6 FSHD myotubes were differentiated and treated for 5 days as indicated above and stained to measure MHC, cleaved caspase-3, and nuclei. Representative images show that cleaved caspase-3 was only detected in FSHD myotubes and not in wild-type controls or after inhibition of the p38 pathway. Six replicates were imaged, and cleaved caspase-3 signal under MHC staining was quantified. (B) Stochastic expression of DUX4 target gene SLC34A2 in C6 FSHD myotubes. Expression of SLC34A2 was measured by immunostaining in similar conditions as image above. No expression was detected in wildtype control or p38 inhibitor-treated myotubes. Signal of SLC34A2 under MHC staining was quantified in two replicates. (C) Concentrationdependent inhibition of the expression of DUX4 target genes is highly correlated to the inhibition of programmed cell death in C6 myotubes. Bars indicate mean \pm S.D. DAPI, 4',6-diamidino-2-phenylindole; WT, wild type.

factors, including myogenic transcription factors like myocyte enhancer factor 2C (Zetser et al., 1999; Simone et al., 2004; Knight et al., 2012; (Segalés et al., 2016)). To determine p38 $\alpha$ / $\beta$-signaling activity in differentiating myoblasts, we measured the levels of phosphorylation of HSP27. As reported previously, we observed increased p38 signaling rapidly upon addition of differentiation media (Supplemental Fig. 2) (Perdiguero et al., 2007). We observed that $\mathrm{p} 38 \alpha / \beta$ inhibitors reduced phosphorylated HSP27 levels with similar $\mathrm{IC}_{50}$ values to that of $M B D 3 L 2$ (Fig. 2B). To further validate our findings, we electroporated FSHD myoblasts with siRNAs against p38 $\alpha$ and $\gamma$, the most abundant p38 MAPKs in skeletal muscle. After 3 days of differentiation, transient knockdown of p38 $\alpha$ showed robust inhibition of expression of MBD3L2 in
FSHD myotubes (Fig. 2C), and no significant effects in fusion were observed (Supplemental Fig. 3). We observed that close to $50 \%$ reduction of MAPK14 (p38 $\alpha$ ) mRNA was sufficient to inhibit $M B D 3 L 2$ expression without impacting myogenesis, and this level of reduction may account for the differences on myogenesis observed between this study and those previously reported using p38 mouse knockout myoblasts (Perdiguero et al., 2007).

Our results suggest the p38 $\alpha$ pathway is an activator of DUX4 expression in FSHD muscle cells undergoing differentiation. To further understand the reduction in DUX4, we measured the expression of DUX4 transcript and protein upon inhibition of $\mathrm{p} 38 \alpha$ and $\beta$. To measure protein, we developed a highly sensitive assay based on the electrochemiluminescent detection of DUX4 on the MSD platform using two previously generated antibodies (Supplemental Fig. 4). We observed that p38 $\alpha / \beta$ inhibition resulted in a highly correlated reduction of DUX4 transcript and protein (Fig. 2D). We concluded this led to the reduction in the expression of DUX4 target gene, $M B D 3 L 2$

p38 $\alpha$ and $\beta$ Inhibition Normalizes Gene Expression of FSHD Myotubes without Impacting the Myogenic Differentiation Program. We further examined the effect of $\mathrm{p} 38 \alpha$ and $\beta$ selective inhibition on myotube formation because this pathway has been linked to muscle cell differentiation (Simone et al., 2004; Perdiguero et al., 2007; Wissing et al., 2014; Segalés et al., 2016a,b). We developed a quantitative assay to measure cell fusion and myotube formation to assess skeletal muscle differentiation in vitro. In this assay, we stained immortalized FSHD myotubes cells using antibodies against MHCs and quantified the number of nuclei detected inside MHC-stained region. This provided a way to quantitate the number of cells that successfully underwent the process of in vitro myogenesis. p38 $\alpha / \beta$ inhibition by LY2228820 and GW856553X (losmapimod) did not impact differentiation of myoblasts into skeletal muscle myotubes. Treated cells fused properly at all tested drug concentrations to levels comparable to the DMSO control (Fig. 3A).

We also further assessed gene expression changes in FSHD myotubes upon $\mathrm{p} 38 \alpha / \beta$ inhibition. We performed RNA-seq analysis of FSHD and WT myotubes after 4 days of treatment with vehicle or $p 38 \alpha / \beta$ inhibitors. Inhibition of the p38-signaling pathway during differentiation did not induce significant transcriptome changes and resulted in fewer than 100 differentially expressed genes [abs $(\mathrm{FC})>4$; FDR $<0.001]$. About $90 \%$ of these differentially expressed genes were known DUX4-regulated transcripts and were all downregulated after p38 $\alpha$ and $\beta$ inhibition (Fig. 3B). This set of DUX4-regulated genes overlapped significantly with genes upregulated in muscle biopsies in patients with FSHD (Wang et al., 2019). Moreover, key driver genes of myogenic programs, such as MYOG, myocyte enhancer factor, and paired box genes, and markers of differentiation, such as myosin subunits and sarcomere proteins, were not affected by p38 inhibition (Fig. 3C).

Inhibition of DUX4 Expression Results in the Reduction of Cell Death in FSHD Myotubes. DUX4 activation and downstream DUX4-regulated target gene expression in muscle cells is toxic, leading to oxidative stress, changes in sarcomere organization, and apoptosis, culminating in reduced contractility and muscle tissue replacement by fat (Block et al., 2013; Bosnakovski et al., 2014; Tawil et al., 2014; Homma et al., 2015; Rickard et al., 2015; Choi et al., 2016). In particular, 
A

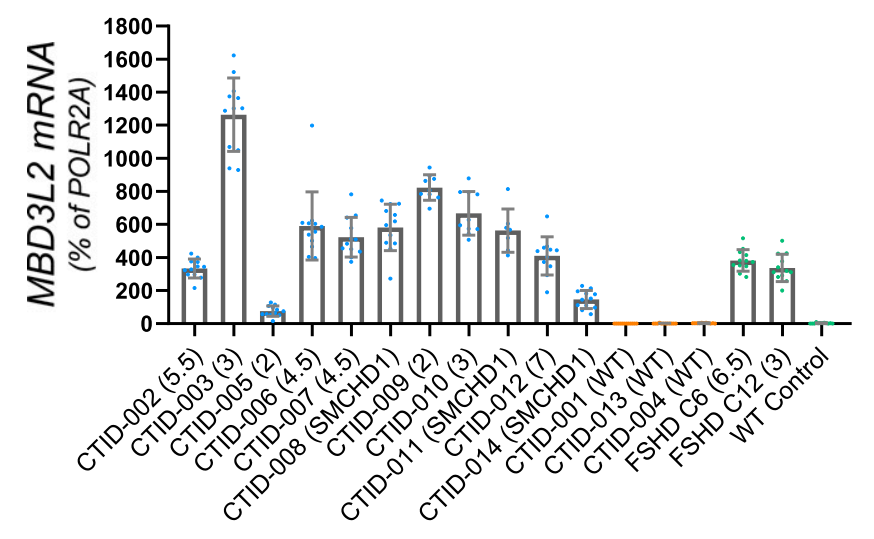

B
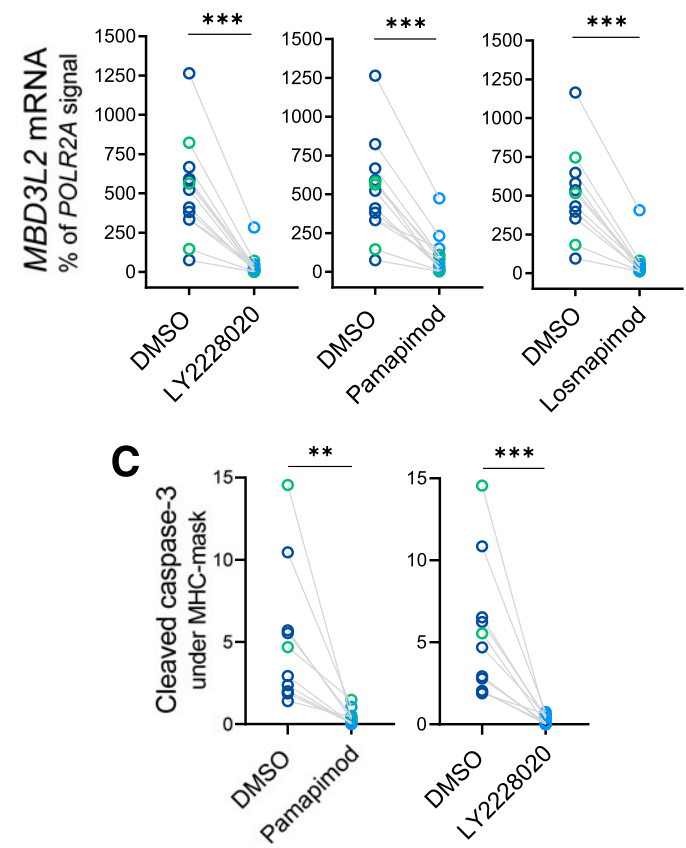

D

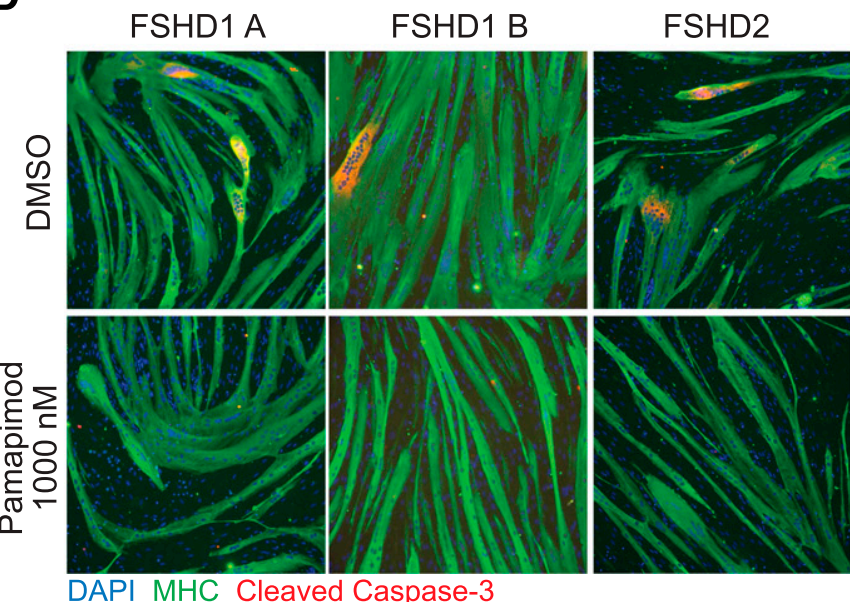

Fig. 5. p38 $\alpha / \beta$ inhibition results in the reduction of DUX4 activity and cell death across a variety of genotypes of FSHD1 and FSHD2 primary myotubes. (A) Levels of $M B D 3 L 2$ expression across different primary and immortalized myotubes determined RT-qPCR. DUX4 activity is only detected in FSHD1/2 lines after 4 days of differentiation. Bars indicate mean \pm S.D., and repeat number is indicated in parenthesis in FSHD1 lines and SMCHD1 mutation for FSHD2 lines used. (B) Inhibition of the p38 $\alpha / \beta$ pathway results in potent reduction of $M B D 3 L 2$ expression activation across the entire set of FSHD primary cells tested. Three apoptotic cells have been detected in skeletal muscle of patients with FSHD, thereby supporting the hypothesis that programmed cell death is caused by aberrant DUX4 expression and contributes to FSHD pathology (Sandri et al., 2001; Statland et al., 2015). To test this hypothesis in vitro, we evaluated the effect of $\mathrm{p} 38 \alpha / \beta$ inhibition on apoptosis in FSHD myotubes. We used an antibody recognizing caspase-3 cleavage products by immunofluorescence to quantify changes in the activation of programmed cell death. Cleavage of caspase-3 is a major step in the execution of the apoptosis-signaling pathway, leading to the final proteolytic steps that result in cell death (Fuentes-Prior and Salvesen, 2004; Dix et al., 2008). We detected activated caspase-3 in FSHD but not in wild-type myotubes and observed a stochastic pattern of expression of DUX4 in FSHD as previously reported (Fig. 4A) (Snider et al., 2010; Jones et al., 2012; van den Heuvel et al., 2019). Levels of cleaved caspase-3 were reduced in a concentration-dependent manner with an $\mathrm{IC}_{50}$ similar to what we observed for inhibition of the p38 pathway and DUX4 expression (Fig. 4B). Moreover, we measured SLC34A2, a DUX4 target gene product using a similar immunofluorescence assay (Fig. 3B). This protein was expressed in a similar stochastic pattern observed for active caspase-3, and its expression was also reduced by $\mathrm{p} 38 \alpha / \beta$ inhibition (Fig. 4, B and C). Our results demonstrate that DUX4 inhibition in FSHD myotubes results in a significant reduction of apoptosis.

p38 $\alpha$ and $\beta$ Inhibition Results in Downregulation of DUX4 Expression and Suppression of Cell Death Across Multiple FSHD1 and FSHD2 Genotypes. FSHD is caused by the loss of repression at the $D 4 Z 4$ locus leading to DUX4 expression in skeletal muscle due to the contraction in the $D 4 Z 4$ repeat arrays in chromosome 4 or by mutations in $S M C H D 1$ and other modifiers, such as DNMT3B. Primary FSHD myotubes were used to study the in vitro efficacy of p38 $\alpha / \beta$ inhibitors across different genotypes. We tested eight FSHD1 primary myoblasts with 2-7 D4Z4 repeat units and three FSHD2 cell lines with characterized SMCHD1 mutations. Upon differentiation, the primary cells tested expressed a wide range of $M B D 3 L 2$ levels (Fig. 5A, number of D4Z4 repeat units or SMCHD1 mutation indicated in parenthesis), comparable to what we and others have observed in other FSHD myotubes (Jones et al., 2012). However, we observed significant inhibition of the DUX4 program expression after treatment with multiple $\mathrm{p} 38 \alpha / \beta$ inhibitors in all primary myotubes tested from patients with FSHD1 and FSHD2 (Fig. 5B). Furthermore, this reduction in the DUX4 program resulted in concomitant reduction of cleaved caspase-3 (Fig. 5C) without any measurable effects on myotube differentiation (Fig. 5D). Our results suggest that the $\mathrm{p} 38 \alpha / \beta$ pathway critically regulates the activation of DUX 4 independently of the mutation driving its expression in FSHD muscle cells.

different inhibitors were used, and each circle indicates a different FSHD cell line tested. FSHD1 in blue and FSHD2 in green. Expression levels were measured by RT-qPCR in six replicates. (C and D) p38 $\alpha / \beta$ pathway inhibition reduces activation of programmed cell death across primary FSHD cell lines with different genotypes. Stochastic activation of caspase3 in a small number of FSHD myotubes was detected by immunostaining and quantified in all lines. Six replicates were used to quantify signal of cleaved caspase-3 under MHC-stained myotubes. Wilconox test, $P$ value $* * 0.002, * * * 0.0002$. DAPI, 4',6-diamidino-2-phenylindole; WT, wild type. 


\section{Discussion}

Recent studies have advanced the understanding of the mechanisms that normally lead to the establishment and maintenance of repressive chromatin at the $D 4 Z 4$ repeats. Similar to other repetitive elements in somatic cells, chromatin at this locus is decorated by DNA methylation and other histone modifications associated with gene silencing, such as H3K27me3 and H3K9me3 (van Overveld et al., 2003; Zeng et al., 2009; Cabianca et al., 2012; van den Boogaard et al., 2016b). Factors involved in the deposition of these modifications like $S M C H D 1$ and $D N M T 3 B$ have been identified by genetic analysis of affected FSHD populations (Lemmers et al., 2012; Calandra et al., 2016; van den Boogaard et al., $2016 \mathrm{~b})$. Other factors that associate with the $D 4 Z 4$ locus like nucleosome remodeling deacetylase (NuRD) and chromatin assembly factor 1 (CAF1) have been identified by biochemical approaches (Campbell et al., 2018). However, sequencespecific transcriptional activators of DUX4 have remained elusive not only in skeletal muscle but also in the regulation of DUX4 in the developing embryo, where this factor is normally expressed. Because of the effects of expression of DUX4 in FSHD and the apparent tissue-specific expression of DUX4 in skeletal muscle, it has been hypothesized that myogenic regulatory elements upstream of the $D 4 Z 4$ repeats participate in the expression of DUX4 in FSHD (Himeda et al., 2014), yet this finding has not led to the identification of other factors that can specifically activate DUX4.

In this study, by modeling FSHD in vitro and screening a library of probe molecules using a highly sensitive and specific assay to detect a DUX4 target gene, we identified p $38 \alpha$ as a novel activator of DUX4 expression in patient-derived FSHD cells. This signaling kinase directly phosphorylates transcription factors involved in myogenesis and may signal directly to activate $D U X 4$ expression in differentiating myoblasts. Using highly selective and potent small molecules extensively characterized previously, we have studied the pharmacological relationships between the inhibition of this signaling pathway and the inhibition of the expression of DUX4, its downstream gene program expression, and its consequences in muscle cells from patients with FSHD. These relationships are maintained across multiple FSHD genotypes, including FSHD1 and FSHD2, indicating that this mechanism acts independent of the genetic lesion present in these patients. Our studies show a specific effect of $\mathrm{p} 38 \alpha$ and $\beta$ inhibition in downregulation of the DUX4 program and normalization of gene expression compared with cells from healthy donors. Notably, no effects in differentiation were detected at the tested concentrations of p38 inhibitor.

Other recent efforts to identify targets for the treatment of FSHD have reported similar studies in which the investigators followed the expression of MBD3L2 as a readout for DUX4 expression or by using a reporter driven by the activity of DUX4 in immortalized FSHD myotubes in vitro (Campbell et al., 2017; Cruz et al., 2018). Our results have reproduced their previous identification of $\beta$-adrenergic agonists and BET inhibitors as inhibitors of DUX4 expression. However, these molecules also caused downregulation of the transcription factor MYOG expression or affected myoblasts fusion at concentrations similar to the half-maximal inhibitory concentration for DUX4 expression inhibition in our model (Supplemental Fig. 1B, lack of fusion indicated by arrow).
Similarly, we also observed that inhibition of phosphodiesterases resulted in DUX4 downregulation, suggesting that cyclic AMP levels during differentiation are also important for its expression as previously reported (Cruz et al., 2018). It remains to be deciphered how all these pathways interconnect to regulate DUX4 expression during the process of in vitro differentiation and, most importantly, in the skeletal muscle tissue of patients with FSHD. In vitro models like the one used in this study, may suffer from diverse limitations. Differences in media, extracellular matrix used as coating in culture plates, and timing in treatments might result in deviation of pharmacological effects observed. However, an independent study recently described in a different in vitro model that $\mathrm{p} 38 \alpha / \beta$ inhibitors inhibit expression of DUX4, further validating findings reported here. Importantly, in this study, they showed that $\mathrm{p} 38 \alpha / \beta$ inhibitors are efficacious in downregulating expression of DUX4 in a xenograft mouse model of FSHD, supporting the idea that this mechanism is a viable therapeutic target in the FSHD muscle. Other approaches to identify therapeutics for FSHD have explored inhibition of the effects downstream of DUX4 activation. These efforts have resulted in the identification of potential targets like P300/CBP (cAMP response element-binding protein) and the hypoxia response pathway, which could help in protecting muscle cells against the toxic effects of DUX4 expression (Bosnakovski et al., 2014). In addition, other groups have directly targeted DUX4 by using antisense oligonucleotides and gene therapy approaches and have demonstrated preclinical efficacy in animal models (Chen et al., 2016a; Ansseau et al., 2017; Wallace et al., 2017).

In humans, previous clinical studies evaluating p38 $\alpha / \beta$ inhibitors in non-FSHD indications under an anti-inflammatory therapeutic hypothesis were tested extensively and shown to be safe and well-tolerated. However, they never met efficacy endpoints in diseases such as rheumatoid arthritis, chronic obstructive pulmonary disease, and acute coronary syndrome (Hill et al., 2008; Damjanov et al., 2009; Hammaker and Firestein, 2010; Barbour et al., 2013; MacNee et al., 2013; Norman, 2015; Patnaik et al., 2016). Here, we present further evidence from in vitro studies that support the therapeutic hypothesis of treatment of FSHD at its root cause, prevention, or reduction of aberrant expression of DUX4 via inhibition of $\mathrm{p} 38 \alpha / \beta$.

\section{Acknowledgments}

We thank Peter Jones, Takako Jones, and Charis Himeda from the University of Nevada, Reno for technical advice and guidance during the development of assays in this manuscript and insightful discussions about the regulation of DUX4 expression. We thank Peter Jones for providing us with constructs for DUX4 overexpression used to validate our DUX4 protein detection assay and Vincent Mouly (Institut Myologie) and Silvère Van der Maarel (Leiden University Medical Center) for providing access to immortalized myoblast lines. In addition, the authors would like to thank members of Fulcrum Therapeutics for helpful discussions throughout the project. We would also like to thank patients participating in previous studies that have provided tissues to generate cell lines used in this manuscript.

\section{Authorship Contributions}

Participated in research design: Rojas, Valentine, Accorsi, Maglio, Shen, Robertson, Kazmirski, Rahl, Tawil, Cadavid, Thompson, Ronco, Chang, Cacace, Wallace.

Conducted experiments: Rojas, Valentine, Accorsi, Maglio, Shen, Robertson. 
Contributed new reagents or analytic tools: Valentine, Accorsi, Kazmirski, Tawil.

Performed data analysis: Rojas, Valentine, Accorsi, Robertson. Wrote or contributed to the writing of the manuscript: Rojas, Wallace.

\section{References}

Ansseau E, Vanderplanck C, Wauters A, Harper SQ, Coppée F, and Belayew A (2017) Antisense oligonucleotides used to target the DUX4 mRNA as therapeutic approaches in FaciosScapuloHumeral muscular dystrophy (FSHD). Genes (Basel) 8.93.

Barbour AM, Sarov-Blat L, Cai G, Fossler MJ, Sprecher DL, Graggaber J, McGeoch AT, Maison J, and Cheriyan J (2013) Safety, tolerability, pharmacokinetics and pharmacodynamics of losmapimod following a single intravenous or oral dose in healthy volunteers. Br J Clin Pharmacol 76:99-106.

Block GJ, Narayanan D, Amell AM, Petek LM, Davidson KC, Bird TD, Tawil R, Moon RT, and Miller DG (2013) Wnt/ $\beta$-catenin signaling suppresses DUX4 expression and prevents apoptosis of FSHD muscle cells. Hum Mol Genet 22: 4661-4672.

Bosnakovski D, Choi SH, Strasser JM, Toso EA, Walters MA, and Kyba M (2014) High-throughput screening identifies inhibitors of DUX4-induced myoblast toxicity. Skelet Muscle 4:4.

Bosnakovski D, da Silva MT, Sunny ST, Ener ET, Toso EA, Yuan C, Cui Z, Walters MA, Jadhav A, and Kyba M (2019) A novel P300 inhibitor reverses DUX4-mediated global histone H3 hyperacetylation, target gene expression, and cell death. Sci Adv 5:eaaw7781.

Brewer GJ, Boehler MD, Jones TT, and Wheeler BC (2008) NbActiv4 medium improvement to Neurobasal/B27 increases neuron synapse densities and network spike rates on multielectrode arrays. J Neurosci Methods 170:181-187.

Cabianca DS, Casa V, Bodega B, Xynos A, Ginelli E, Tanaka Y, and Gabellini D (2012) A long ncRNA links copy number variation to a polycomb/trithorax epigenetic switch in FSHD muscular dystrophy. Cell 149:819-831.

Calandra P, Cascino I, Lemmers RJLF, Galluzzi G, Teveroni E, Monforte M, Tasca G, Ricci E, Moretti F, van der Maarel SM, et al. (2016) Allele-specific DNA hypomethylation characterises FSHD1 and FSHD2. J Med Genet 53:348-355.

Campbell AE, Oliva J, Yates MP, Zhong JW, Shadle SC, Snider L, Singh N, Tai S, Hiramuki Y, Tawil R, et al. (2017) BET bromodomain inhibitors and agonists of the beta-2 adrenergic receptor identified in screens for compounds that inhibit DUX4 expression in FSHD muscle cells. Skelet Muscle 7:16.

Campbell AE, Shadle SC, Jagannathan S, Lim J-W, Resnick R, Tawil R, van der Maarel SM, and Tapscott SJ (2018) NuRD and CAF-1-mediated silencing of the D4Z4 array is modulated by DUX4-induced MBD3L proteins. eLife 7:e31023.

Campbell RM, Anderson BD, Brooks NA, Brooks HB, Chan EM, De Dios A, Gilmour R, Graff JR, Jambrina E, Mader M, et al. (2014) Characterization of LY2228820 dimesylate, a potent and selective inhibitor of p38 MAPK with antitumor activity. Mol Cancer Ther 13:364-374.

Chen JC, King OD, Zhang Y, Clayton NP, Spencer C, Wentworth BM, Emerson CP Jr., and Wagner KR (2016a) Morpholino-mediated knockdown of DUX4 toward facioscapulohumeral muscular dystrophy therapeutics. Mol Ther 24:1405-1411.

Chen K, Dobson RC, Lucet IS, Young SN, Pearce FG, Blewitt ME, and Murphy JM (2016b) The epigenetic regulator Smchd1 contains a functional GHKL-type ATPase domain. Biochem J 473:1733-1744.

Choi SH, Gearhart MD, Cui Z, Bosnakovski D, Kim M, Schennum N, and Kyba M (2016) DUX4 recruits p300/CBP through its C-terminus and induces global H3K27 acetylation changes. Nucleic Acids Res 44:5161-5173.

Coulthard LR, White DE, Jones DL, McDermott MF, and Burchill SA (2009) p38(MAPK): stress responses from molecular mechanisms to therapeutics. Trends Mol Med 15:369-379.

Cruz JM, Hupper N, Wilson LS, Concannon JB, Wang Y, Oberhauser B, PatoraKomisarska K, Zhang Y, Glass DJ, Trendelenburg A-U, et al. (2018) Protein kinase A activation inhibits DUX4 gene expression in myotubes from patients with facioscapulohumeral muscular dystrophy. J Biol Chem 293:11837-11849.

Cuenda A and Rousseau S (2007) p38 MAP-Kinases pathway regulation, function and role in human diseases. Biochim Biophys Acta 1773:1358-1375.

Damjanov N, Kauffman RS, and Spencer-Green GT (2009) Efficacy, pharmacodynamics, and safety of VX-702, a novel p38 MAPK inhibitor, in rheumatoid arthritis: results of two randomized, double-blind, placebo-controlled clinical studies. $\mathrm{Ar}$ thritis Rheum 60:1232-1241.

Deenen JCW, Arnts H, van der Maarel SM, Padberg GW, Verschuuren JJGM, Bakker E, Weinreich SS, Verbeek ALM, and van Engelen BGM (2014) Populationbased incidence and prevalence of facioscapulohumeral dystrophy. Neurology $\mathbf{8 3}$ 1056-1059.

de Greef JC, Lemmers RJLF, van Engelen BGM, Sacconi S, Venance SL, Frants RR Tawil R, and van der Maarel SM (2009) Common epigenetic changes of D4Z4 in contraction-dependent and contraction-independent FSHD. Hum Mutat 30: 1449-1459

Dion $\mathrm{C}$, Roche S, Laberthonnière $\mathrm{C}$, Broucqsault N, Mariot V, Xue S, Gurzau AD, Nowak A, Gordon CT, Gaillard M-C, et al. (2019) SMCHD1 is involved in de novo methylation of the DUX4-encoding D4Z4 macrosatellite. Nucleic Acids Res 47: $2822-2839$

Dix MM, Simon GM, and Cravatt BF (2008) Global mapping of the topography and magnitude of proteolytic events in apoptosis. Cell 134:679-691.

Fehr S, Unger A, Schaeffeler E, Herrmann S, Laufer S, Schwab M, and Albrecht W (2015) Impact of p38 MAP kinase inhibitors on LPS-induced release of TNF- $\alpha$ in whole blood and primary cells from different species. Cell Physiol Biochem 36: $2237-2249$

Fuentes-Prior P and Salvesen GS (2004) The protein structures that shape caspase activity, specificity, activation and inhibition. Biochem $J$ 384:201-232.
Geng LN, Yao Z, Snider L, Fong AP, Cech JN, Young JM, van der Maarel SM, Ruzzo WL, Gentleman RC, Tawil R, et al. (2012) DUX4 activates germline genes, retroelements, and immune mediators: implications for facioscapulohumeral dystrophy. Dev Cell 22:38-51.

Hammaker D and Firestein GS (2010) "Go upstream, young man": lessons learned from the p38 saga. Ann Rheum Dis 69 (Suppl 1):i77-i82.

Hill RJ, Dabbagh K, Phippard D, Li C, Suttmann RT, Welch M, Papp E, Song KW Chang KC, Leaffer D, et al. (2008) Pamapimod, a novel p38 mitogen-activated protein kinase inhibitor: preclinical analysis of efficacy and selectivity. $J$ Pharmacol Exp Ther 327:610-619.

Himeda CL, Debarnot C, Homma S, Beermann ML, Miller JB, Jones PL, and Jones TI (2014) Myogenic enhancers regulate expression of the facioscapulohumeral muscular dystrophy-associated DUX4 gene. Mol Cell Biol 34:1942-1955.

Himeda CL, Jones TI, and Jones PL (2015) Facioscapulohumeral muscular dystrophy as a model for epigenetic regulation and disease. Antioxid Redox Signal 22: 1463-1482.

Homma S, Beermann ML, Boyce FM, and Miller JB (2015) Expression of FSHDrelated DUX4-FL alters proteostasis and induces TDP-43 aggregation. Ann Clin Transl Neurol 2:151-166.

Jagannathan S, Shadle SC, Resnick R, Snider L, Tawil RN, van der Maarel SM, Bradley RK, and Tapscott SJ (2016) Model systems of DUX4 expression recapitulate the transcriptional profile of FSHD cells. Hum Mol Genet 25: $4419-4431$

Jansz N, Chen K, Murphy JM, and Blewitt ME (2017) The epigenetic regulator SMCHD1 in development and disease. Trends Genet 33:233-243.

Jones TI, Chen JC, Rahimov F, Homma S, Arashiro P, Beermann ML, King OD, Miller JB, Kunkel LM, Emerson CP Jr., et al. (2012) Facioscapulohumeral muscular dystrophy family studies of DUX4 expression: evidence for disease modifiers and a quantitative model of pathogenesis. Hum Mol Genet 21:4419-4430.

Jones TI, King OD, Himeda CL, Homma S, Chen JCJ, Beermann ML, Yan C, Emerson CP Jr., Miller JB, Wagner KR, et al. (2015) Individual epigenetic status of the pathogenic D4Z4 macrosatellite correlates with disease in facioscapulohumera muscular dystrophy. Clin Epigenetics 7:37.

Jones TI, Yan C, Sapp PC, McKenna-Yasek D, Kang PB, Quinn C, Salameh JS, King OD, and Jones PL (2014) Identifying diagnostic DNA methylation profiles for facioscapulohumeral muscular dystrophy in blood and saliva using bisulfite sequencing. Clin Epigenetics 6:23.

Keren A, Tamir Y, and Bengal E (2006) The p38 MAPK signaling pathway: a major regulator of skeletal muscle development. Mol Cell Endocrinol 252:224-230.

Knight JD, Tian R, Lee RE, Wang F, Beauvais A, Zou H, Megeney LA, Gingras A-C, Pawson T, Figeys D, et al. (2012) A novel whole-cell lysate kinase assay identifies substrates of the p38 MAPK in differentiating myoblasts. Skelet Muscle 2:5.

Krementsov DN, Thornton TM, Teuscher C, and Rincon M (2013) The emerging role of p38 mitogen-activated protein kinase in multiple sclerosis and its models. $\mathrm{Mol}$ Cell Biol 33:3728-3734.

Krom YD, Dumonceaux J, Mamchaoui K, den Hamer B, Mariot V, Negroni E, Geng LN, Martin N, Tawil R, Tapscott SJ, et al. (2012) Generation of isogenic D4Z4 contracted and noncontracted immortal muscle cell clones from a mosaic patient: a cellular model for FSHD. Am J Pathol 181:1387-1401.

Kyriakis JM and Avruch J (2001) Mammalian mitogen-activated protein kinase signal transduction pathways activated by stress and inflammation. Physiol Rev 81:807-869.

Lemmers RJ, van der Vliet PJ, Klooster R, Sacconi S, Camaño P, Dauwerse JG, Snider L, Straasheijm KR, van Ommen GJ, Padberg GW, et al. (2010) A unifying genetic model for facioscapulohumeral muscular dystrophy. Science 329: $1650-1653$

Lemmers RJLF, Tawil R, Petek LM, Balog J, Block GJ, Santen GWE, Amell AM, van der Vliet PJ, Almomani R, Straasheijm KR, et al. (2012) Digenic inheritance of an SMCHD1 mutation and an FSHD-permissive D4Z4 allele causes facioscapulohumeral muscular dystrophy type 2. Nat Genet 44:1370-1374.

MacNee W, Allan RJ, Jones I, De Salvo MC, and Tan LF (2013) Efficacy and safety of the oral p38 inhibitor PH-797804 in chronic obstructive pulmonary disease: a randomised clinical trial. Thorax 68:738-745

Martin ED, Bassi R, and Marber MS (2015) p38 MAPK in cardioprotection - are we there yet? $\mathrm{Br} J$ Pharmacol 172:2101-2113.

Norman P (2015) Investigational p38 inhibitors for the treatment of chronic obstructive pulmonary disease. Expert Opin Investig Drugs 24:383-392.

Oliva J, Galasinski S, Richey A, Campbell AE, Meyers MJ, Modi N, Zhong JW, Tawil R, Tapscott SJ, and Sverdrup FM (2019) Clinically advanced p38 inhibitors suppress DUX4 expression in cellular and animal models of facioscapulohumeral muscular dystrophy. J Pharmacol Exp Ther 370:219-230.

Patnaik A, Haluska P, Tolcher AW, Erlichman C, Papadopoulos KP, Lensing JL, Beeram M, Molina JR, Rasco DW, Arcos RR, et al. (2016) A first-in-human phase I study of the oral p38 MAPK inhibitor, ralimetinib (LY2228820 dimesylate), in patients with advanced cancer. Clin Cancer Res 22:1095-1102.

Perdiguero E, Ruiz-Bonilla V, Gresh L, Hui L, Ballestar E, Sousa-Victor P, BaezaRaja B, Jardí M, Bosch-Comas A, Esteller M, et al. (2007) Genetic analysis of p38 MAP kinases in myogenesis: fundamental role of p38 $\alpha$ in abrogating myoblast proliferation. EMBO J 26:1245-1256.

Rickard AM, Petek LM, and Miller DG (2015) Endogenous DUX4 expression in FSHD myotubes is sufficient to cause cell death and disrupts RNA splicing and cell migration pathways. Hum Mol Genet 24:5901-5914.

Sandri M, El Meslemani AH, Sandri C, Schjerling P, Vissing K, Andersen JL, Rossin K, Carraro U, and Angelini C (2001) Caspase 3 expression correlates with skeletal muscle apoptosis in Duchenne and facioscapulo human muscular dystrophy. A potential target for pharmacological treatment? J Neuropathol Exp Neurol 60: 302-312.

Segalés J, Islam ABMMK, Kumar R, Liu Q-C, Sousa-Victor P, Dilworth FJ, Ballestar E, Perdiguero E, and Muñoz-Cánoves P (2016) Chromatin-wide and transcriptome profiling integration uncovers p38 $\alpha$ MAPK as a global regulator of skeletal muscle differentiation. Skelet Muscle 6:9. 
Segalés J, Perdiguero E, and Muñoz-Cánoves P (2016) Regulation of muscle stem cell functions: a focus on the p38 MAPK signaling pathway. Front Cell Dev Biol 4:91.

Shadle SC, Zhong JW, Campbell AE, Conerly ML, Jagannathan S, Wong C-J, Morello TD, van der Maarel SM, and Tapscott SJ (2017) DUX4-induced dsRNA and MYC mRNA stabilization activate apoptotic pathways in human cell models of facioscapulohumeral dystrophy. PLoS Genet 13:e1006658.

Simone C, Forcales SV, Hill DA, Imbalzano AN, Latella L, and Puri PL (2004) p38 pathway targets SWI-SNF chromatin-remodeling complex to muscle-specific loci. Nat Genet 36:738-743.

Snider L, Geng LN, Lemmers RJ, Kyba M, Ware CB, Nelson AM, Tawil R, Filippova GN, van der Maarel SM, Tapscott SJ, et al. (2010) Facioscapulohumeral dystrophy: incomplete suppression of a retrotransposed gene. PLoS Genet 6:e1001181.

Statland JM, Odrzywolski KJ, Shah B, Henderson D, Fricke AF, van der Maarel SM, Tapscott SJ, and Tawil R (2015) Immunohistochemical characterization of facioscapulohumeral muscular dystrophy muscle biopsies. J Neuromuscul Dis 2 : 291-299.

Statland JM and Tawil R (2014) Risk of functional impairment in Facioscapulohumeral muscular dystrophy. Muscle Nerve 49:520-527.

Tasca G, Pescatori M, Monforte M, Mirabella M, Iannaccone E, Frusciante R, Cubeddu T, Laschena F, Ottaviani P, and Ricci E (2012) Different molecular signatures in magnetic resonance imaging-staged facioscapulohumeral muscular dystrophy muscles. PLoS One 7:e38779.

Tawil R, Kissel JT, Heatwole C, Pandya S, Gronseth G, and Benatar M; Guideline Development, Dissemination, and Implementation Subcommittee of the American Academy of Neurology; Practice Issues Review Panel of the American Association of Neuromuscular \& Electrodiagnostic Medicine (2015) Evidence-based guideline summary: evaluation, diagnosis, and management of facioscapulohumeral muscular dystrophy: report of the Guideline Development, Dissemination, and Implementation Subcommittee of the American Academy of Neurology and the Practice Issues Review Panel of the American Association of Neuromuscular \& Electrodiagnostic Medicine. Neurology 85:357-364.

Tawil R, van der Maarel SM, and Tapscott SJ (2014) Facioscapulohumeral dystrophy: the path to consensus on pathophysiology. Skelet Muscle 4:12.

Thorley M, Duguez S, Mazza EMC, Valsoni S, Bigot A, Mamchaoui K, Harmon B, Voit T, Mouly V, and Duddy W (2016) Skeletal muscle characteristics are preserved in hTERT/cdk4 human myogenic cell lines. Skelet Muscle 6:43.

Underwood DC, Osborn RR, Kotzer CJ, Adams JL, Lee JC, Webb EF, Carpenter DC, Bochnowicz S, Thomas HC, Hay DW, et al. (2000) SB 239063, a potent p38 MAP kinase inhibitor, reduces inflammatory cytokine production, airways eosinophil infiltration, and persistence. J Pharmacol Exp Ther 293:281-288.

van den Boogaard ML, Lemmers RJ, Camaño P, van der Vliet PJ, Voermans N, van Engelen BG, Lopez de Munain A, Tapscott SJ, van der Stoep N, Tawil R, et al. (2016a) Double SMCHD1 variants in FSHD2: the synergistic effect of two SMCHD1 variants on D4Z4 hypomethylation and disease penetrance in FSHD2. Eur J Hum Genet 24:78-85. van den Boogaard ML, Lemmers RJLF, Balog J, Wohlgemuth M, Auranen M, Mitsuhashi S, van der Vliet PJ, Straasheijm KR, van den Akker RFP, Kriek M, et al. (2016b) Mutations in DNMT3B modify epigenetic repression of the D4Z4 repeat and the penetrance of facioscapulohumeral dystrophy. Am J Hum Genet 98:1020-1029. van den Heuvel A, Mahfouz A, Kloet SL, Balog J, van Engelen BGM, Tawil R, Tapscott SJ, and van der Maarel SM (2019) Single-cell RNA sequencing in facioscapulohumeral muscular dystrophy disease etiology and development. Hum $\mathrm{Mol}$ Genet 28:1064-1075.

van Overveld PGM, Lemmers RJFL, Sandkuijl LA, Enthoven L, Winokur ST, Bakels F, Padberg GW, van Ommen G-JB, Frants RR, and van der Maarel SM (2003) Hypomethylation of D4Z4 in 4q-linked and non-4q-linked facioscapulohumeral muscular dystrophy. Nat Genet 35:315-317.

Wallace LM, Saad NY, Pyne NK, Fowler AM, Eidahl JO, Domire JS, Griffin DA, Herman AC, Sahenk Z, Rodino-Klapac LR, et al. (2017) Pre-clinical safety and offtarget studies to support translation of AAV-mediated RNAi therapy for FSHD. Mol Ther Methods Clin Dev 8:121-130.

Wang LH, Friedman SD, Shaw D, Snider L, Wong C-J, Budech CB, Poliachik SL, Gove NE, Lewis LM, Campbell AE, et al. (2019) MRI-informed muscle biopsies correlate MRI with pathology and DUX4 target gene expression in FSHD. Hum Mol Genet 28:476-486.

Whiddon JL, Langford AT, Wong C-J, Zhong JW, and Tapscott SJ (2017) Conservation and innovation in the DUX4-family gene network. Nat Genet 49:935-940.

Whitmarsh AJ (2010) A central role for p38 MAPK in the early transcriptional response to stress. BMC Biol 8:47.

Wissing ER, Boyer JG, Kwong JQ, Sargent MA, Karch J, McNally EM, Otsu K, and Molkentin JD (2014) P38 $\alpha$ MAPK underlies muscular dystrophy and myofiber death through a Bax-dependent mechanism. Hum Mol Genet 23:5452-5463.

Yao Z, Snider L, Balog J, Lemmers RJLF, Van Der Maarel SM, Tawil R, and Tapscott SJ (2014) DUX4-induced gene expression is the major molecular signature in FSHD skeletal muscle. Hum Mol Genet 23:5342-5352.

Zarubin T and Han J (2005) Activation and signaling of the p38 MAP kinase pathway. Cell Res 15:11-18.

Zeng W, de Greef JC, Chen Y-Y, Chien R, Kong X, Gregson HC, Winokur ST, Pyle A Robertson KD, Schmiesing JA, et al. (2009) Specific loss of histone H3 lysine 9 trimethylation and $\mathrm{HP} 1 \gamma /$ cohesin binding at D4Z4 repeats is associated with facioscapulohumeral dystrophy (FSHD). PLoS Genet 5:e1000559.

Zetser A, Gredinger E, and Bengal E (1999) p38 mitogen-activated protein kinase pathway promotes skeletal muscle differentiation. Participation of the Mef2c transcription factor. $J$ Biol Chem 274:5193-5200.

Address correspondence to: L. Alejandro Rojas, Fulcrum Therapeutics, 26 Landsdowne St., 5th Floor, Cambridge MA 02139. E-mail: arojas@ fulcrumtx.com 